\title{
Stage IIA Ovarian Cancer AJCC v8
}

National Cancer Institute

\section{Source}

National Cancer Institute. Stage IIA Ovarian Cancer A/CC v8. NCI Thesaurus. Code C139969.

Stage IIA includes: T2a, N0, M0. T2a: Ovarian cancer with tumor extension and/or implants on the uterus and/or fallopian tube(s) and/or ovaries. N0: No regional lymph node metastasis. M0: No distant metastasis. (AJCC 8th Ed.) 